\title{
Descriptions, Ambiguity, and Representationalist Theories of Interpretation
}

\begin{abstract}
Theories of descriptions tend to involve commitments about the ambiguity of descriptions. For example, sentences containing descriptions are widely taken to be ambiguous between de re, de dicto, and intermediate interpretations and are sometimes thought to be ambiguous between the former and directly referential interpretations. I provide arguments to suggest that none of these interpretations are due to ambiguities (or indexicality). On the other hand, I argue that descriptions are ambiguous between the above family of interpretations and what may be called 'institutional' as well as generic interpretations. My arguments suggest an adequate theory of descriptions may require considerable rethinking. Most contemporary theories of descriptions appear to be committed to one or more claims about the ambiguity of descriptions that I reject in this paper. I suggest that my observations provide a reason to renew efforts to develop a theory of descriptions within a representationalist theory of interpretation.
\end{abstract}

Keywords Descriptions $\cdot$ Ambiguity $\cdot$ Generics $\cdot$ Uniqueness Presupposition $\cdot$ Representationalist Theories of Interpretation

\section{Introduction}

Natural language gives us the flexibility to make assertions about particular individuals and objects, as well as more general assertions. Part of this flexibility derives from de- 
scriptions like 'the winner', or 'a doctor'. Sentences including descriptions of this sort can often yield different interpretations in different contexts, including, for example, de re, de dicto, and "referential" interpretations. An important question is how these various interpretations relate to the linguistic meaning, or the semantic contribution, of the descriptions and the sentences in which they occur. As has long been recognized, the availability of different interpretations of an expression in context does not entail the ambiguity of the expression (Hintikka 1973; Zwicky and Sadock 1975). Lexical ambiguities, in which a word has multiple lexicalized interpretations, and structural ambiguities, in which a string of words can be assigned multiple syntactic structures, are two potential sources of interpretive variability in context. Language offers other potential sources, such as pragmatic implicatures (Grice 1975; Atlas 2005) and indexicality (Kaplan 1989). Hence our question: Granted, a single sentence involving a description may be used to express different propositions in different contexts: Is this because the sentence is ambiguous, or is this rather a matter of some other feature of language? A theory of the linguistic meaning of descriptions cannot proceed without committing itself to an answer. This makes surprising the shortage of discussions that would investigate directly which of the many different interpretations of descriptions are due to ambiguity.

A notable exception can be found in this journal. Sennett (2002) devotes an entire paper to a linguistic argument against the ambiguity of general and Donnellan-style referential interpretations (Donnellan 1966), which has been alleged by various theorists (Reimer 1998; Devitt 2004; Amaral 2008). I believe it is time to begin investigating the ambiguity of descriptions more systematically. Almost all theorists seem to think that 
sentences including descriptions are sometimes ambiguous between de re, de dicto, and certain "intermediate" interpretations. For many students, the classical view that there is a relevant scope ambiguity in such sentences may well be the only view they encounter (Neale 1990). More recently, some theorists have postulated a lexical/structural ambiguity within 'the $F$ ' (Elbourne 2005), or a structural ambiguity within attitude report verb phrases (Keshet forthcoming). It is surprisingly hard to find a contemporary theory that is not committed to an ambiguity in this area, an observation to which I will return later. In this paper, I present arguments to suggest the surprising conclusion that sentences including descriptions of the form 'the $F$ ' and 'a $F$ ' are not in fact ambiguous with respect to de re, de dicto and intermediate interpretations. I also provide further support for the conclusion that descriptions are not ambiguous with respect to referential and general interpretations. By contrast, I argue that descriptions are genuinely ambiguous between ordinary and generic interpretations (as in "a beagle makes a great companion") which partially removes the motivation for a view like that presented by Sharvy (1980) that treats ordinary and generic interpretations together. The question in what ways descriptions are ambiguous also intersects with the ongoing debate about the role of uniqueness conditions in definite descriptions. I argue that descriptions are likely ambiguous between ordinary and what may be called 'institutional' interpretations, defusing a class of Ludlow and Segal's (2004) apparent counterexamples to the claim that definite descriptions, ordinarily interpreted, involve a uniqueness condition. I conclude with the observation that if my arguments are correct, we have a serious motivation to renew efforts to produce a viable theo- 
ry of descriptions within a representationalist theory of interpretation, departing from the current mainstream.

\section{De re, de dicto, and intermediate interpretations}

Descriptions can be used to make general assertions that are independent of particular objects. Consider (1) adapted from Quine (1956):

(1) I want to find a dog that talks.

(1) can be interpreted as announcing a quixotic desire for a dog - any dog - with a certain special talent. To understand (1) in this way is to give it a 'de dicto' interpretation. ${ }^{1}$ (1) can also be interpreted as announcing a desire to locate a particular dog about which the speaker has serious delusions. To understand (1) in this way is to give it a 'de $r e^{\prime}$ interpretation. ${ }^{2}$

Further interpretations become available if more attitude verbs are added (Kripke 1977; Neale 1990). Consider the following scenario: Hoover prepares a public statement alleging that the Berrigans have a plan to capture a member of the kitchen staff at the embassy. In fact the staff is made up of undercover US officials. According to Hoover,

\footnotetext{
${ }^{1}$ Quine distinguished 'notional' and 'relational' interpretations instead. I merely seek to attach a familiar label to a roughly characterized family of interpretations.

${ }^{2}$ Similar interpretive possibilities are afforded by sentences like 'I want to find six dogs that talk,' 'I want to find most dogs that talk,' etc. For the purposes of this paper, my concern will exclusively be definite and indefinite descriptions of the form 'the $F$ ' and 'a $F$ '.
} 
however, the Berrigans think they are only targeting kitchen staff. The next morning, we say:

(2) Hoover has charged that the Berrigans plan to kidnap a US official.

Hoover did not charge that any particular official was targeted, so the interpretation of (2) in the discourse is not de re. At the same time, Hoover did not charge that the Berrigans thought of the target of their alleged plot as a US official, so the interpretation is not $d e$ dicto either; it is an "intermediate" interpretation.

While both definite and indefinite descriptions doubtlessly allow de re, de dicto, and intermediate interpretations, the question arises whether descriptions or the sentences containing them are in fact ambiguous between those interpretations. On a classical view, sentences including descriptions are characterized by quantifier scope ambiguity (Neale 1990; Russell 1905). On an alternative view, descriptions are lexically or struturally ambiguous between at least some of the relevant interpretations (Elbourne 2005). I shall now suggest that views of this sort are vulnerable to a powerful form of argument that appeals to a linguistic test for semantic ambiguity.

Zwicky and Sadock (1975) observe that ambiguous constituents cannot shift their interpretation as part of a verb phrase (VP) under ellipsis. For example,

(3) Peter went to a bank and Jack did too.

(4) Peter saw her duck and so did Mary. 
(3), which contains the lexically ambiguous 'bank', cannot be literally interpreted as a claim that Peter went to a financial institution and Jack went to a river bank. Similarly, (4), which is structurally ambiguous, cannot be literally interpreted as a claim that Peter saw someone's pet duck and that Mary saw someone crouch. A corresponding constraint applies to quantifier scope ambiguities, as in expressions like 'to introduce two boys to every girl' and 'three boys admire every teacher'.

(5) First I introduced two boys to every girl and then you did.

(6) Three boys admire every teacher and three girls do, too.

If the left conjunct in a conjunctive VP-ellipsis construction is ambiguous with respect to quantifier scope (e.g., the relative scope of 'a' and 'every' in the examples), the relative scope of the quantifiers in the right conjunct must be the same as in the left conjunct (Fox 1999). A corresponding constraint also applies to indexical expressions:

(7) Lois hit him and so did Mary.

(8) Lois came yesterday but Mary did not.

We have to interpret (7) as claiming that Lois and Mary hit the same person, and (8) as claiming that Mary did not come on the same day as Lois. All of these constraints presumably reflect the more general grammatical constraint that an elided VP must be 'par- 
allel' to its antecedent VP (Fiengo and May 1994). In sum, if it is possible to shift the interpretation of a constituent under VP ellipsis, then that constituent is not ambiguous with respect to the relevant difference in interpretation. If a forced shift in interpretation makes an otherwise grammatical sentence seem ungrammatical, then the constituent is most likely ambiguous. It is plausible that we unreflectively exploit these constraints in certain verbal jokes: the grammatical violation involved in forcing two simultaneous interpretations of an ambiguous constituent is part of what adds frisson to puns. ${ }^{3}$

We can now examine what data from VP ellipsis suggests about the alleged ambiguity between de re and de dicto interpretations. Consider the following scenario: John has a cult-like attachment to a certain novelist. At a public reading, John sees the novelist nervously fingering a shiny object, though he cannot make out what it is and certainly does not recognize that the object is a lighter. John would love to have that particular object as a talisman, believing it to have become magically charged by the novelist. Elsewhere, Mary is shopping around for a lighter in a mall.

(9) John wants a lighter and so does Mary.

(10) John wants a lighter and so does Mary. John ends up stealing it and Mary buys one at the cigar emporium.

(9) seems like a coherent continuation of the discourse and seems true in context. Intuitively, we want to give 'a lighter' a de re interpretation for John. For Mary, we want to

\footnotetext{
${ }^{3}$ For example: A king is free to execute his laws and his citizens as he sees fit.
} 
give 'a lighter' a de dicto interpretation, resulting in a mixed interpretation of 'a lighter' in (9). Consider the other possibilities. An interpretation on which 'a lighter' is taken de dicto would not work as a report of John's desire, because has no idea that the novelist is handling a lighter. An interpretation on which 'a lighter' is taken de re would not work as a report of Mary's desire, since she merely desires "relief from lighterlessness".

Is there a possibility for a uniform interpretation of (9) in context that avoids a mix of de re and de dicto interpretations? We need to consider what Fodor has called "non-specific transparent" interpretations. On this type of interpretation, "John wants a $P$ " means that John wants relief from a lack of objects in a certain set, where that set is contained in the set of objects denoted by ' $P$ ', but where the descriptive material encoded by ' $P$ ' may not be part of John's attitude. A paraphrase of "John wants a lighter" along these lines would be "lighters are such that John wants one of them." Now, as the case is described, it just does not seem correct to say that John has a non-specific attitude toward a set of things that happens to be contained in the set of lighters. Rather, he has an irrational attachment to a particular object, whatever classes that object turns out to belong to. On a "non-specific transparent" interpretation, the left conjunct of (9) just does not seem likely to be true in light of the background provided. In sum, no uniformly de re, de dicto, or non-specific-transparent interpretation seems to capture that (9) seems true in context.

A further reason to think that (9) in context is indeed given a mixed interpretation is that we can continue the discourse in a way that involves discourse dependencies on both specific (e.g. de re) and non-specific (including de dicto) interpretations of 'a light- 
er'. (10) interpreted in the place of (9) in the context under consideration seems acceptable.

The acceptability of (10) in the context under consideration suggests a mixed de $r e$ and de dicto interpretation, because the use of the word 'it' clashes with non-specific interpretations (including de dicto) ${ }^{4}$ and the use of 'one' clashes with specific interpretations, as (11) and (12) illustrate.

(11) Jack wants a lighter and would be happy with any Zippo. \#He ends up stealing it.

(12) There is a particular lighter at the antique shop that Molly wants. \#She ends up buying one [where she buys the particular lighter that she wants].

Again, it seems that there is a natural interpretation of (9) in the context provided that is mixed, switching from de re to de dicto across VP ellipsis. Our general principle is: When mixed interpretations are possible, the construction that is explicit in one conjunct but elided in the other is not ambiguous.

Note that the claim is not that we would normally use a sentence like (9) to convey both a de re and a de dicto interpretation, or that such mixed interpretations are independently salient for a sentence like (9) uttered in isolation. The claim is that mixed interpretations of (9) are not ruled out by grammatical constraints, as they would be, if descriptions were relevantly ambiguous.

\footnotetext{
${ }^{4}$ Ioup (1975); Keshet (2008)
} 
Contrast the apparent lack of constraint on mixed interpretations in (9) with the clear constraint on mixed interpretations in examples (3)-(8), respectively involving lexical ambiguity, structural ambiguity, scope ambiguity, and indexicality. Indefinite descriptions simply are not subject to the constraints on interpretation under VP ellipsis that would be predicted on the hypothesis that attitude verb-phrases containing them are ambiguous or even indexical with respect to de re and de dicto interpretations. This suggests that indefinite descriptions simply are not ambiguous or indexical in this way.

Moving on, applying the same test to definite descriptions is slightly more involved. Even if someone only has a de dicto attitude that one would normally report with a de dicto attitude report, one can nevertheless often truly utter a de re attitude report to report her attitude. This would reflect the notion, in Salmon' words, that "virtually whenever one asserts that the such-and-such is thus-and-so, one thereby asserts of the suchand-such, if there is exactly one, that he/she/it is thus-and-so." (Salmon 2004). This makes it harder to find a case in which capturing truth conditions would require both a de re and a de dicto interpretation of the same definite description under ellipsis.

One way to sidestep this problem is to include modal embeddings. Consider the following scenario: Mike is watching a tennis tournament at the stadium with his wife Cathy and would love to meet the winner, whoever he turns out to be. Cathy could not care less who wins at tennis. However, if only her husband didn't exist, she would love to meet a certain handsome man sitting close to the court. Unbeknownst to her, the man is the tennis player Raphael, who was favored to win the tournament before an accidental injury. 
(13) [In the actual world,] Mike wants to meet the winner, and, in a nearby possible world, so would Cathy.

(13) seems likely to be true in the context provided. Intuitively, the report is de dicto for Mike and de re for Cathy. A de re interpretation of the left conjunct does not seem true, since the tournament is ongoing. The right conjunct seems true because in a nearby possible world, Cathy's husband does not exist and Raphael is the winner of the tournament. And in any nearby world where Cathy's husband does not exist, she would love to meet Raphael. A de re interpretation of the right conjunct with the definite description outside of the modal embedding does not seem true, because Raphael is not even in the tournament. A de dicto interpretation with the definite description inside the modal embedding does not seem true, because Cathy is plainly interested in the particular individual Raphael in the contextually relevant nearby worlds, and it is not the case that in the contextually relevant nearby worlds, Cathy would want to meet whoever happens to win the tournament. A non-specific transparent interpretation with the definite description outside the modal embedding does not seem true either, because the contextually relevant nearby worlds plainly do not make it true that whoever wins in the actual world is such that in a nearby world, Cathy would want to meet that person.

To capture the intuition that (13) seems likely to be true in the context provided, the left conjunct requires a de dicto interpretation of 'the winner', while the right conjunct requires a de re interpretation inside the modal embedding. This suggests that (13) 
in context involves a mixed interpretation, shifting across VP ellipsis from a de dicto interpretation of 'the winner' to a de re interpretation. It appears that definite descriptions, like indefinite descriptions, are not ambiguous with respect to de re and de dicto interpretations.

Finally, we can examine whether intermediate interpretations are due to an ambiguity. Consider the following scenario: Hoover made a statement alleging that the Berrigans plan to capture a member of the kitchen staff of an embassy, which Hoover claims to be made up of undercover Task Force operatives. According to Hoover, the Berrigans believe that they are targeting only kitchen staff. Meanwhile, the police, who are operating independently, bugged the Berrigans' hideout and recorded them resolving to kidnap the first operative they can find. Unlike the Berrigans, the police know that there are no operatives. Unlike Hoover, who has his own secret agenda, the police make this clear. By the next morning,

(14) Hoover has charged that the Berrigans plan to kidnap an operative, and so have the police.

(14) seems to be a coherent conclusion within the discourse, even though Hoover makes an intermediate charge, while the police make a de dicto charge. There are no operatives according to the discourse, so we could not appeal to a uniformly de re interpretation. Hoover is not charging that the Berrigans believe they are targeting an operative, so we cannot use a uniformly de dicto interpretation. What about an "intermediate non-specific 
transparent" interpretation? Such an interpretation may be roughly paraphrased by "Hoover has charged that operatives are such that the Berrigans plan to kidnap one of them and the police has charged that operatives are such that the Berrigans plan to kidnap one of them." The trouble is that the police are not charging that there are any operatives, so this interpretation cannot capture that (14) seems like a coherent continuation of the discourse. It appears that we need to shift from an intermediate to a de dicto interpretation across VP ellipsis in (14), which suggests that there is no de dicto/intermediate ambiguity for indefinite descriptions. In the interest of space, I will omit a parallel test case for definite descriptions.

\section{Singular interpretations}

Definite descriptions are sometimes interpreted as directly referential, akin to demonstratives or proper names (Donnellan 1966). Consider the following scenario: A man who is on trial for Smith's murder enters the court room and begins to shout incoherently. Few know that he is an innocent mental patient and that the real culprit is sane. One spectator makes the following remark to another. The listener happens to be one of the few who know that the mental patient is innocent; moreover he knows that he is one of the few people who knows this. 
(15)

The murderer of Smith is insane. ${ }^{5}$

We intuitively expect the listener to be able to interpret (15) as true, giving it an interpretation that just asserts of the individual who just entered the courtroom that he is insane. A referential interpretation of (15) does not take it as part of the asserted content that someone has the property of having murdered Smith. Devitt argues that "the vast majority of uses of definites are referential" (Devitt 2007). Other authors agree (Bach 2004; Reimer 1998).

A growing number of theorists hold that descriptions are in fact ambiguous between referential and general interpretations (Reimer 1998; Devitt 2004; Amaral 2008). A classical consideration against the ambiguity theory is that if an expression is ambiguous in one language, one can normally find languages in which the ambiguity is explicitly resolved (Kripke 1977). Kripke suggests that 'the' is not ambiguous since there do not appear to be any languages that distinguish what one might call a "singular" 'the ${ }_{1}$ from what one might call a "general" 'the ${ }_{2}$ '. As Bach put it, it would be "a massive crosslinguistic coincidence," if 'the' turned out to be ambiguous (Bach 2004).

If 'the' is indeed not ambiguous in the relevant way, there should be grammatical observations in English that are evidence of absence of ambiguity. Sennett has argued that 'the' fails something like the test for ambiguity discussed above, with respect to referential and general interpretations (Sennett 2002). Consider (16) in the following scenar-

\footnotetext{
${ }^{5}$ I use 'the murderer of Smith' because it has become a standard example, even though it sounds somewhat awkward. In his classic paper, Donnellan uses both 'the murderer of Smith' and 'Smith's murderer.' See Donnellan (1966), 286.
} 
io adapted from Sennett: We are about to start a republican revolution against a monarchy in transition. Just before dawn, a secret council will crown a Queen. We have no idea who will become Queen. Unlike you, I don't know that all that is left of the monarchy is the secret council. We have covertly entered the castle and are hiding in preparation for an overwhelming assault at dawn. From our hiding place, we a see a young man strut by in splendid golden armor worthy of a prince, singing a song deriding 'the republican dogs' (though in fact, unbeknownst to me, the man is not a prince). Angrily, I say:

The Prince and Queen will die at dawn. ${ }^{6}$

Intuitively, your interpretation of (16) in context is true. However, the intuitive interpretation involves a referential as well as a general interpretation of a definite description. The intuitive interpretation may be paraphrased by, "that guy will die at dawn and the Queen, whoever she turns out to be, will die at dawn.” A mix of a referential and a general interpretation is required to capture the intuitive truth conditions of (16) interpreted in context.

If we were to interpret both 'the Prince' and '<the> Queen' as general, then (16) would be false, because there is no Prince. This would conflict with the intuition that (16) in context seems likely to be true. In any case, it is just implausible that 'the Prince' is interpreted in a general way in the example. With respect to 'the Prince', this case is rele-

\footnotetext{
${ }^{6}$ As Sennett observes, one could replace 'die at dawn' with a verb like 'met' in a modified scenario, should there be a worry that 'the Prince and Queen' is interpreted collectively. However, this worry does not seem urgent.
} 
vantly like Donnellan's original examples of referentially interpreted definite descriptions, such as (15).

Could we interpret both 'the Prince' and '<the> Queen' referentially? This avenue seems closed as well. At the time of utterance, there simply is no determinate Queen, and both speaker and hearer know this. This is precisely the sort of case in which we need a general interpretation.

In sum, to capture the intuitive interpretation of (16) in context, we need a referential interpretation as well as a general interpretation. Sennett argues that this shows that 'the' is not ambiguous between referential and object independent interpretations.

One potential worry about Sennett's argument is that determiner-sharing constructions are not in general as straightforwardly acceptable as, say, VP ellipsis constructions. Most people seem to have the intuition that determiner-sharing is blocked if too much descriptive material intervenes between the overt determiner and the "sharing site". This means that it is harder to construct a broad range of test cases. The best solution here will be to construct additional independent test cases that do not rely on determiner sharing.

If definite descriptions are not ambiguous between referential interpretations and general interpretations, it should be possible to find further evidence using VP-ellipsis constructions. Sennett does not provide a clear argument from VP-ellipsis, but it seems to me that such an argument can be constructed. Consider the following scenario: We are

\footnotetext{
${ }^{7}$ For example, an anonymous reviewer suggested that it is impossible to interpret, "the speaker of the house and minority leader of the senate will die at dawn" as saying that two individuals will die at dawn.
} 
working for a corporation that is in the process of electing a new CEO. From our desks, we can see into a closed conference room in which the board of directors is about to elect the new CEO. We can also see into a waiting room in which a manager named Jack is waiting to meet whoever ends up being the boss. I misinterpret what I see in the conference room and conclude that Smith has been elected CEO. You happen to notice this. The phone rings. I answer. George is on the line and asks to speak to Smith, planning to influence the election. Since you are in charge of regulating access, I report to you:

George wants to talk to the CEO and so does Jack.

What is conveyed by (17) in context seems true. George wants to talk to a specific individual (Smith), and 'the CEO' in the left conjunct is interpreted referentially. Jack wants to talk to whoever turns out to be the boss, and he does not think that there is a determinate $\mathrm{CEO}$ as yet. The implicit '<the CEO>' in the right conjunct is therefore not interpreted referentially.

If we interpret 'the CEO' de dicto in both conjuncts, (17) is false since George does not believe that Smith, the man he wants to speak to, is the CEO. If we interpret 'the CEO' de re in both conjuncts, (17) is false, since there is no CEO yet. If we interpret 'the CEO' referentially for both conjuncts in (17), we run into the problem that Jack does not want to talk to anybody in particular.

This time, the entire definite description was subjected to ellipsis. Yet, we still managed to obtain an interpretation that shifted from a referential to a general interpreta- 
tion across conjuncts. This provides further evidence that definite descriptions are not ambiguous with respect to referential and general interpretations.

\section{Generic interpretations of descriptions}

We have just argued that while sentences involving descriptions admit of a wide variety of interpretations, the data so far do not suggest that descriptions are ambiguous with respect to those interpretations. Descriptions may have referential and general uses, in the sense that sentences involving them may be used to express propositions about particular objects, and also general propositions. But the evidence we have adduced suggests that these interpretations are not due to a genuine ambiguity. Now, the same linguistic tests suggest that descriptions are, by contrast, ambiguous with respect to different sorts of interpretations. These interpretations are more similar to generics than they are to paradigmatic descriptions.

(18) A beagle makes a great hunting dog for the jungle.

(19) The Golden Retriever is a great family pet.

It has been argued that a theory of descriptions should provide a unified account of both ordinary interpretations of descriptions and generic interpretations (Sharvy 1980). I will argue that the difference between ordinary and generic descriptions in fact involves an ambiguity.

First, consider indefinites: 
(20) A friend of mine is an attorney.

(21) An enemy of mine is an attorney.

(22) A solicitor just is an attorney.

(23) *A friend of mine is an attorney, and a solicitor is too.

(24) A friend of mine is an attorney, and an enemy of mine is too.

(25) *A beagle rescued us and is a great hunting dog. [interpreting 'is a great hunting dog' as making a statement about beagles generically]

(26) *A Corolla makes a great cheap vehicle and was parked in the driveway.

(27) A Corolla is parked across the street and was seen in the driveway earlier.

(24) markedly contrasts with (23). We can use ellipsis in (24) to assert both (20) and (21), but we cannot use ellipsis in to make relevant double assertions in (23), (25), and (26). This suggests that indefinite descriptions are in fact ambiguous between normal indefinite and generic interpretations.

Could the data be explained by a relevant ambiguity of the English copula 'is'? (25) and (26) are unacceptable even though 'is' is not even part of the ellipsis site, so the relevant constraint on interpretation cannot generally be due to an ambiguity of ' $Y$ is $X$ '. In fact, it appears that the English copula 'is' in any case isn't ambiguous in a way that would account for unacceptability of (23). What would the relevant ambiguity consist in? 'A solicitor is an attorney' and 'my friend is an attorney' could be seen as cutting across a distinction between an identity use of 'is' and a predicative use of 'is'. It is possible that 
when we interpret 'an attorney' generically in (25), we are using an identity reading of 'is' in a way that might be roughly paraphrased as "attorney-ism is identical to barristerism.” When we interpret 'an attorney' as a normal indefinite description, we would then say that we are using a predicational reading of 'is' in a way that might be paraphrased as "some friend of mine has the property of being an attorney." However, if we examine the copula 'is' in ellipsis constructions involving both identity and predication, we find that it does not behave as though it were ambiguous between identity and predicative uses.

(28) Karl is not only handsome but also the discoverer of the AIDS vaccine. [predica tive use/identity use]

(29) *Karl fired not only John but also the wood stove.

(30) The little boy is Fauntleroy, and hence aristocratic. [identity use/predicative use]

(31) *The little boy fired James, and then the stove.

(32) [A: Hayworth is English but is Jude?] B: Jude is Hayworth and [as you would thus grant] English. [identity use/predicative use]

(33) *The pot-roast is ready to eat, and so are the dinner guests.

(34) The little boy is King James, and Duncan at least aristocratic.

These examples suggest that 'is' is not ambiguous between identity and predicative uses in English, unlike, say, 'fire' is lexically ambiguous between 'let go' and 'ignite' or 'ready to eat' is structurally ambiguous with respect to argument role assignment. (34) shows that shifting from identity to a predicative use is even acceptable under pseudo- 
gapping, which creates even stronger constraints than VP ellipsis. ${ }^{8}$ In sum, it is implausible that the unacceptability of examples like (23) can be accounted for by an ambiguity of the English copula 'is'.

Moving on, we can now consider generic interpretations of definite descriptions.

(35) John is the president.

(36) Mighty Mouse is not the President.

(37) The monotreme is the oviparous mammal.

(38) *The monotreme is the oviparous mammal and Mighty Mouse is not.

(39) [A monotreme and Mighty mouse just entered, and we're wondering which of them lays eggs. Correcting my misperception, you say:] The monotreme is the oviparous mammal and Mighty Mouse is not.

(40) John is the president and Mighty Mouse is not.

Similar to the pattern with indefinite descriptions, it seems that (38) contrasts markedly with (39) and (40). 'The oviparous mammal' does not seem to support crossed interpretations involving both generic and ordinary readings. As just argued, it is highly unlikely that an ambiguity in the copula 'is' can account for this data. It appears that both definite and indefinite descriptions are ambiguous between generic and ordinary interpretations. If descriptions are ambiguous in this way, it is not a requirement on a theory of

\footnotetext{
${ }^{8}$ For example, pseudo-gapping, unlike VP ellipsis, rules out voice mismatches. See Merchant (2008)
} 
ordinary interpretations of descriptions that it capture generic interpretations as well, pace Sharvy. After all, it is not a requirement on, say, a semantics for 'bank' that an account of one sense of 'bank' has to generalize to its other sense. Even if generic senses of descriptions are in some interesting way related to their ordinary senses, the presence of an ambiguity justifies postulating two separate lexical entries or syntactic structures for the two senses.

\section{Institutional definites and uniqueness}

A theory of descriptions must capture the fact that definite descriptions "have something to do with" a claim of uniqueness. On a classical Russellian view, definite descriptions assert that there is a unique individual that satisfies the description. On other views, definite descriptions presuppose a unique referent or at least unique identifiability, though the uniqueness condition is not part of what is asserted by their utterances (Szabó 2003).

There are apparent counterexamples to the notion that there is an obligatory connection between definite descriptions and any kind of uniqueness condition. One important sort of alleged counterexamples discussed by Ludlow and Segal (2004) and Karttunen (1968) seem to me to belong to a class of what one may call institutional readings,' as in the following example: ${ }^{9}$

(41) John went to the pub. (British English)

\footnotetext{
${ }^{9}$ I use 'institutional readings' for want of a better label and to distinguish them from the broader class of interpretations that are sometimes called 'weak definites'.
} 
Ludlow and Segal point out that (41) is fine in British English. However, a normal utterance of (41) neither presupposes that there is only one pub in the world or that there is a pub that can be uniquely identified in conversation. Does this mean that theories on which ordinary definite descriptions are connected to a uniqueness condition are in trouble? If 'the pub' and other similar definite descriptions are ambiguous between ordinary and institutional interpretations, then theories that require ordinary interpretations to be tied to a uniqueness condition are momentarily in the clear. ${ }^{10}$ It appears that expressions like 'the pub' are indeed ambiguous in this way.

One hallmark of lexical ambiguity is that patterns of ambiguity in even very similar languages and dialects are often not the same, reflecting the fact that the lexicon is in important ways arbitrary. Note that (41) does not support the relevant interpretation in American English. The 'institutional' use of 'the pub' is specific to a certain dialect. If institutional readings of definite descriptions are lexicalized, then which nouns can be used with the definite article to yield an institutional interpretation should be subject to significant cross-linguistic variation. This prediction is borne out. For example, one cannot get an institutional interpretation of 'def. article + coffee' in English or of 'def. article + Kaffee' in German. However, one can get such an interpretation of 'def. article + café' in Spanish. ${ }^{11}$

\footnotetext{
${ }^{10}$ Note that there are other types of prima facie counterexamples, which are beyond the scope of this paper. My concern here is only with what I call 'institutional readings'.

${ }^{11}$ I thank André Estévez-Torres for the linguistic data on Spanish.
} 
(42) \#John is drinking the coffee.

(43) \#John trinkt den Kaffee.

(44) John esta tomando el café.

Similarly, you cannot get an institutional interpretation of 'def. article + café' in English or Spanish, but you can in German:

(45) \#John went to the café.

(46) \#John fue al café.

(47) John ist in's Café gegangen.

These subtle patterns cannot be explained by general pragmatic factors independent of particular languages. The relevant interpretations seem to be of lexical origin. This is not to say that it will always be easy to find a pair of languages that relevantly differs for every case of this sort.

In sum, the particular pattern of cross-linguistic differences in the availability of institutional readings of definite descriptions points to independently lexicalized interpretations. This suggests that descriptions are indeed ambiguous between ordinary and institutional readings. As a result, a theory of institutional descriptions does not have to be continuous with a theory of ordinary descriptions, and institutional readings are not coun- 
terexamples to a "uniqueness" requirement associated with ordinary definite descriptions. $^{12}$

\section{Prospects for the theory of descriptions: Representationalist theories of in- terpretation}

I have argued that descriptions are ambiguous between ordinary interpretations and generic interpretations, and that definite descriptions are ambiguous between ordinary and institutional interpretations. If this is correct, then a theory of ordinary interpretations of descriptions does not automatically have to account for institutional interpretations of definite descriptions or for generic interpretations of descriptions. Since those interpretations are due to genuine ambiguity, a semantic theory may plausibly postulate independent semantic values for those interpretations. This lessens the burden for a theory of descriptions.

The most surprising conclusion of this paper has been that descriptions may not be ambiguous between referential, de re, de dicto, and intermediate interpretations. If this is correct, then sentences including descriptions have one univocal linguistic meaning, which leaves open whether we should give it a referential, de re, de dicto, or intermediate interpretation. I suggest that this conclusion gives new support to the notion that the correct theory of descriptions requires a representationalist theory of interpretation..$^{13}$ On such a theory, particular interpretations of sentences correspond to components of (men-

\footnotetext{
${ }^{12}$ This is not to say that there aren't other types of cases that potentially put pressure on the uniqueness condition.

${ }^{13}$ Views of this sort were first presented by Karttunen (1976), Heim (1982) and Kamp (1981).
} 
tal) representations of the discourse in which they occur. The intuitive truth conditions of interpretations of utterances in discourse correspond to the truth conditions of the (mental) representations that the interpreter builds of the discourse. Linguistic meaning serves as an input to the procedure that constructs those mental representations. On such a view, it is a natural avenue to say that the linguistic meaning of certain sentences fails to completely specify the (mental) representation that should be constructed in interpreting them, merely constraining the interpreter to a certain range of possibilities. A representationalist theory of interpretation can thus naturally accommodate the view that sentences including descriptions are not ambiguous (or indexical), even though they allow for a range of possible interpretations with distinct truth conditions. For example, on a cartoon version of Heim's (1982) view, the linguistic meaning of 'John wants a dog' univocally determines a representation with a free variable along the lines of 'John wants $\operatorname{dog}(\mathrm{x})$ '. At the level of representation of the discourse, we then say that this variable gets bound by an operator that is independent of linguistic meaning. If the operator takes wide scope, we have a de re interpretation. If the operator takes narrow scope, we have a de dicto interpretation. However, the difference is not marked in the linguistic meaning of 'John wants a dog'; there is no de relde dicto ambiguity in the sentence. This is merely to illustrate how one particular representationalist theory can avoid postulating a de relde dicto ambiguity. It is hard to see how one can avoid postulating ambiguities here without a representationalist theory. Since Heim (1990) abandoned her particular version of a representationalist theory, there has been a relative decrease in interest in such theories in many circles, which may explain why so many recent theories are committed to ambiguity anal- 
yses of descriptions. If descriptions are indeed not ambiguous with respect to de re, de

dicto, intermediate, and referential interpretations, as I have argued in this paper, it is worth renewing efforts toward a theory of descriptions in a representationalist framework.

\section{References}

Amaral, F. S. (2008). Definite descriptions are ambiguous. Analysis 68.4, 288-297.

Atlas, J. (2005). Logic, Meaning, and Conversation. New York: Oxford University Press.

Bach, K. (2004). Descriptions: Points of Reference. In A. Bezuidenhout and M. Reimer (eds.), Descriptions and Beyond. Oxford: Oxford University Press.

Devitt, M. (2007). Referential Descriptions and Conversational Implicatures. EUJAP, $3(2), 7-32$.

Devitt, M. (2004). The Case for Referential Descriptions. In A. Bezuidenhout and M. Reimer (Eds.), Descriptions and Beyond. Oxford: Oxford University Press.

Donnellan, K. (1966). Reference and Definite Descriptions. Philosophical Review, 75, 281304.

Elbourne, P. (2005). Situations and Individuals. Cambridge: MIT Press.

Fara, D. published as Graff, D. (2003). Desires, Scope, and Tense. Philosophical Perspectives 17(1), 141-163.

Fodor, J. (1970). The Linguistic Description of Opaque Contexts. PhD thesis, MIT.

Fiengo, R. and May, R. (1994). Indices and Identity. Cambridge: MIT Press.

Fox, D. (1999). Focus, parallelism, and accommodation. In T. Matthews and D. Strolovitch (Eds.), Proceedings of the Ninth Conference on Semantics and Linguistic Theory (70-90). Ithaca, NY: CLC Publications.

Grice, H. P. (1975). Logic and coversation. In J. Kimball (Ed.), Syntax and Semantics, 3, New York: Academic Press, 139-151.

Heim, I. (1990). E-type pronouns and donkey anaphora. Linguistics and Philosophy 13, 137178.

Heim, I. (1982). The Semantics of Definite and Indefinite Noun Phrases, Ph.D. Thesis, University of Massachusetts, Amherst.

Hintikka, K. J. J. (1973). Grammar and logic: some borderline problems. In K. J. J. Hintikka, J. M. E. Moravcsik, and P. Suppes (Eds.), Approches to natural language: Proceedings of the 1970 Stanford workshop on grammar and semantics. Dordrecht: D. Reidel, 197-214.

Ioup, G. (1975). Some universals for quantifier scope. Syntax and Semantics 4, 37-58.

Kamp, H. (1981). "A Theory of Truth and Semantic Interpretation," in J. Groenendijk et al., (eds.). Formal Methods in the Study of Natural Language. Amsterdam: Matematisch Centrum.

Kaplan, D. (1989). Demonstratives. In J. Almog and J. Perry (Eds.), Themes from Kaplan. New York: Oxford University Press, 481-563. 
Karttunen, L. (1976). Discourse referents. In J. D. McCawley, ed., Syntax and Semantics 7: Notes from the linguistic underground. New York: Academic Press, 363-385.

Karttunen, L. (1968). What makes definite noun phrases definite? RAND Corporation report P-3871.

Keshet, E. (forthcoming). Split intensionality: A new scope theory of de re and de dicto.

Keshet, E. (2008). Good Intensions: Paving Two Roads to a Theory of the De Re/De Dicto Dis tinction. PhD thesis, MIT.

Kripke, S. (1977). Speaker Reference and Semantic Reference. In French, Uehling, and Wettstein (Eds.), Contemporary Perspectives in the Philosophy of Language (6-27). Minneapolis: University of Minnesota Press.

Ludlow, P. and Segal, G. (2004). On a unitary semantical analysis for definite and indefinite descriptions. In A. Bezuidenhout and M. Reimer (Eds.), Descriptions and Beyond: An Interdisciplinary Collection of Essays on Definite and Indefinite Descriptions. Oxford: Oxford University Press.

Merchant, J. (2008). An asymmetry in voice mismatches in VP-ellipsis and pseudogapping. Linguistic Inquiry 39.1, 169-179.

Neale, S. (1990). Descriptions. Cambridge: MIT Press.

Reimer, M. (1998). Donnellan's Distinction/Kripke's Test. Analysis 58, 89-100.

Russell, B. (1905). On Denoting. Mind 14, 479-493.

Salmon, N. (2004). The Good, the Bad, and the Ugly. In A. Bezuidenhout and M. Reimer (Eds.), Descriptions and Beyond. New York: Oxford University Press, 230-260.

Sharvy, R. (1980). A More General Theory of Definite Descriptions. The Philosophical Review, 89, 607-623.

Spector, I. (2009). Hebrew floating quantifiers. In M. Butt and T. H. King (Eds.), Proceedings of the LFG09 Conference. Palo Alto: CSLI Publications, 521-540.

Sennett, A. (2002). An Ambiguity Test for Definite Descriptions. Philosophical Studies, $111,81-95$.

Szabó, Z.G. (2000). Descriptions and Uniqueness. Philosophical Studies, 101, 29-57.

Zwicky, A. M. and Sadock, J. M. (1975). Ambiguity tests and how to fail them. In Kimball (Ed.), Syntax and Semantics 4 (1-36). New York: Academic Press. 